\title{
INVESTIGATION AND COMPARISON OF DYNAMIC INTERACTION MODELS OF VEHICLE-TRACK SYSTEMS
}

\author{
SEyed-Ali Mosayebi \\ School of Railway Engineering, Iran University of Science and Technology, Tehran, Iran \\ e-mail: mosayebi@iust.ac.ir \\ JabBar-Ali Zakeri, Morteza Esmaeili \\ School of Railway Engineering, Center of Excellence in Railway Transportation, \\ Iran University of Science and Technology, Tehran, Iran \\ e-mail: zakeri@iust.ac.ir; m_esmaeili@iust.ac.ir
}

\begin{abstract}
The current study is devoted to comparison between vehicle-track dynamic interaction models focusing on responses of both vehicle and track components. In this regard, at the beginning, equations of a two-dimensional, 10 degrees of freedom vehicle model are derived, and then the equations of various track model types including one to five layers are derived. The coupled model of the vehicle and various types of track structures are simultaneously solved by using a numerical integration method. Moreover, numerical results are compared with those measured in the field and the validity of results is confirmed. In the next Section of the work, by comparison of both the vehicle and track responses in various track models, the applicability range of each track model is defined. Results for the track without rail irregularity indicate that there are no noticeable differences between track model types for estimating carbody accelerations, wheel-rail contact forces, rail velocities and accelerations when the equivalent method is used. However, the responses of rail displacements and track support forces are different between various track models. Therefore, in the railway track problems, the type of the track model should be determined based on the research purpose.
\end{abstract}

Keywords: railway tracks, track multi-layer models, vehicle model, vehicle-track dynamic interaction, field measurements

\section{Introduction}

Today, the rail transportation system has attracted great attention by all countries in the world. In this regard, precise modeling of ballasted tracks has considerable importance in the appropriate understanding of behavior of both track components and vehicles. For evaluating the dynamic response of railway tracks caused by moving vehicles, various track models have been proposed by various researchers. For instance, Cai and Reymond (1994) simulated the track beam system on a Winkler foundation caused by the wheel/rail impact force. Thambiratnam and Zhuge (1996) analyzed railway track structures as beams on an elastic foundation caused by moving loads with the finite element method. Kerr (2003) reviewed the problems related to analysis and design of railway track engineering. Kerr (2000) investigated different methods of estimating the rail support modulus. Frýba (2013) analyzed the issues related to beams due to various moving loads. Suzuki et al. (2005) studied the effects of rail joins on dynamic behavior of the railway track caused by moving vehicles. Bogacz and Czyczula (2008) investigated responses of a beam on the elastic foundation due to a moving load. Uzzal et al. $(2008,2009)$ presented a pitch plane model including a three-layer track system caused by railway vehicles. Zakeri et al. (2009) studied dynamic behavior of ballasted tracks by considering the train-track interaction 
model. Xia et al. (2010) and Weining et al. (1996) evaluated the effects of moving train vibrations by modeling the railway track. Xia et al. (2013) simulated the train-track-viaduct dynamic model for reducing vibrations. Real et al. (2012) investigated the vertical deflection of ballasted tracks by considering various parameters of railway tracks. Puzavac et al. (2012) determined the effects of track stiffness on railway performance due to a vertical load. Rezvani et al. (2013) studied dynamic responses of railway bridges under moving vehicle loads. Montalbán et al. (2013) analyzed mechanical properties of railway tracks by using the finite element method. Dahlberg (2001) investigated behavior of railway track settlements by using the finite element method. Wang et al. (2015) theoretically and experimentally studied the settlements of foundations in railways. In another study, Zakeri et al. (2016) investigated the effects of moving light and heavy railway vehicles on dynamic behavior of railway tracks. Mosayebi et al. (2016) investigated the effects of moving locomotive on dynamic behavior of railway tracks in field tests and numerical analyses. Mosayebi et al. (2017) examined the effects of the railway ballast and embankment on dynamic behavior of ballasted tracks. Although various vehicle-track interaction models have been developed by various researchers, no study can be found which has compared all models and justified using of each model for railway track dynamic response assessment. Therefore, in this study, various applicable types of railway track models including one to five layer models are developed and their results are compared. In this regard, firstly, equations of railway vehicle motion are presented and then various types of applicable track structure models are described and their equations are derived. Subsequently, by coupling both vehicle and track matrices, the equivalent stiffness and damping concept is presented for the mentioned vehicle-track equations for each case. Afterwards, the whole system of equations is solved numerically. In order to confirm the validity of the numerical results, they are compared with those obtained by field measurements. In the last Section of the paper, comprehensive comparison of track models is carried out to show the applicability range of their results for practical uses.

\section{Equations of motion of the vehicle}

For simulating the vehicle model, at first, the equations of its parts are derived and then a whole matrix is formed. As observed from Fig. 1, the vehicle model consists of three main parts which are carbody, bogies and wheels. The carbody and each bogie have 2 degrees of freedom including vertical and rotational motions. Moreover, each wheel has 1 degree of freedom including vertical motion. Therefore, the vehicle model has 10 degrees of freedom. The vehicle parts are connected with a series of springs and dampers. Table 1 presents the derived equations of different vehicle parts.

In Table $1, M_{c}, M_{t}$, and $M_{w}$ are masses of the carbody, bogie and wheel, respectively. In addition, $J_{c}$ and $J_{t}$ are inertial moments of the carbody and bogie, respectively. Parameters of $K_{w}$ and $K_{t}$ are stiffness coefficients, whereas $C_{w}$ and $C_{t}$ are damping coefficients of the primary and secondary suspension, respectively. Moreover, $Q_{w i}$ is the wheel-rail contact force for the $i$-th wheel, which is calculated as $Q_{w i}=C_{H}\left(X_{w i}-X_{R}\right)^{3 / 2}$. The parameters $C_{H}, X_{w i}$, and $X_{R}$ are the Hertzian spring, $i$-th wheel and rail displacement, respectively. Moreover, the parameters $L_{t}$ and $L_{c}$ are half distances of two wheels and two bogie centers of 1.25 and $9.5 \mathrm{~m}$, respectively (Zakeri et al., 2009). After deriving the equations of the vehicle parts, the vehicle mass, damping and stiffness matrices are achieved.

\section{Railway track motion equations}

According to the literature (Leaflet No. 301, 2002), applicable railway track models can be categorized in five types. These models are tracks with one layer including rail parts, tracks 


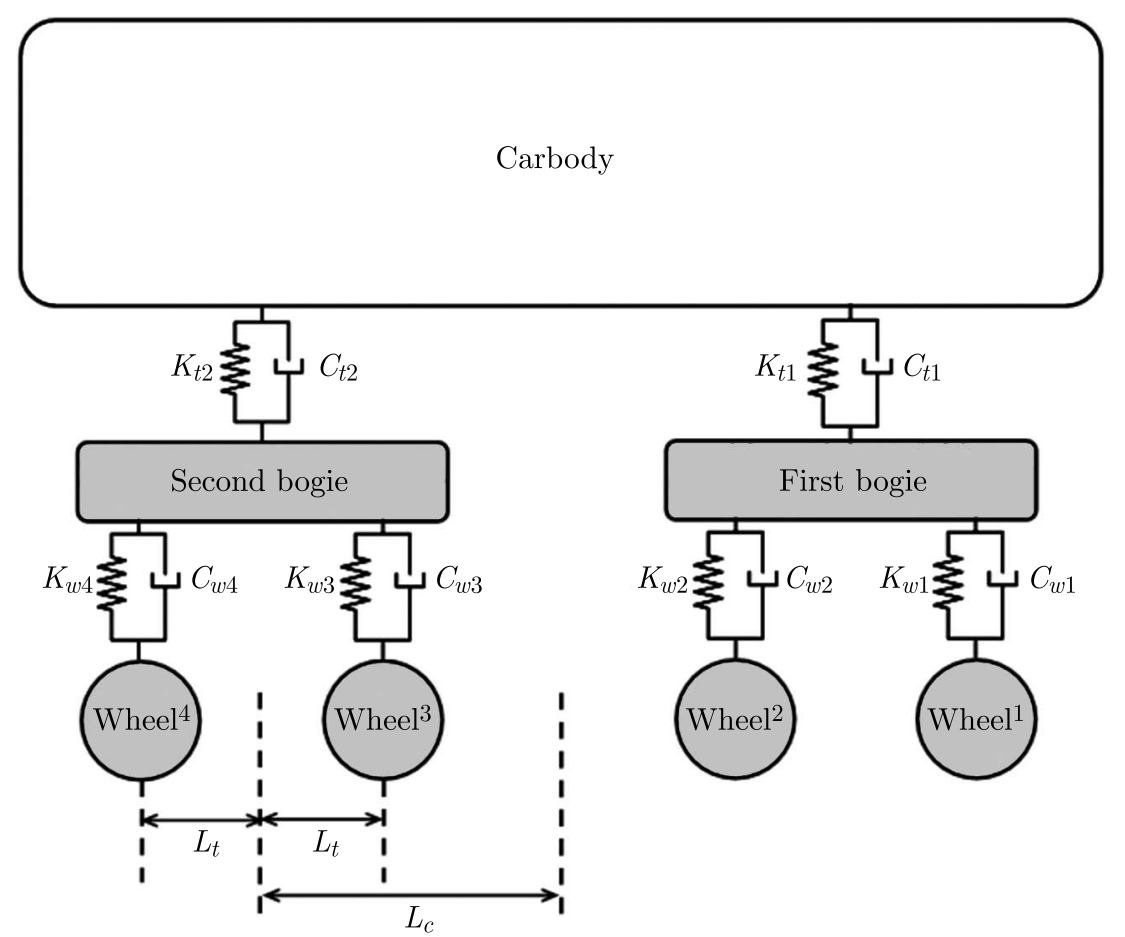

Fig. 1. The vehicle multi-body system

Table 1. The derived equations of motion of the vehicle parts

\begin{tabular}{|c|c|}
\hline Vehicle parts & Equations \\
\hline $\begin{array}{l}\text { Vertical motion of } \\
\text { carbody }\end{array}$ & $\begin{aligned} M_{c} \dot{X}_{c}+K_{t 1}\left(X_{c}-\right. & \left.X_{t 1}\right)+K_{t 2}\left(X_{c}-X_{t 2}\right)+C_{t 1}\left(\dot{X}_{c}-\dot{X}_{t 1}\right) \\
& +C_{t 2}\left(\dot{X}_{c}-\dot{X}_{t 2}\right)=0\end{aligned}$ \\
\hline $\begin{array}{l}\text { Rotational motion of } \\
\text { carbody }\end{array}$ & $\begin{array}{l}J_{c} \ddot{\theta}_{c}+K_{t 1} L_{c}\left(\theta_{c} L_{c}-X_{t 1}\right)+K_{t 2} L_{c}\left(\theta_{c} L_{c}+X_{t 2}\right) \\
+C_{t 1} L_{c}\left(\dot{\theta}_{c} L_{c}-\dot{X}_{t 1}\right)+C_{t 2} L_{c}\left(\dot{\theta}_{c} L_{c}+\dot{X}_{t 2}\right)=0 \\
\end{array}$ \\
\hline $\begin{array}{l}\text { Vertical motion of } \\
\text { the first bogie }\end{array}$ & $\begin{array}{c}M_{t 1} \ddot{X}_{t 1}+K_{t 1}\left(X_{t 1}-X_{c}-\theta_{c} L_{c}\right)+K_{w 1}\left(X_{t 1}-X_{w 1}\right) \\
\quad+K_{w 2}\left(X_{t 1}-X_{w 2}\right)+C_{t 1}\left(\dot{X}_{t 1}-\dot{X}_{c}-\dot{\theta}_{c} L_{c}\right) \\
\quad+C_{w 1}\left(\dot{X}_{t 1}-\dot{X}_{w 1}\right)+C_{w 2}\left(\dot{X}_{t 1}-\dot{X}_{w 2}\right)=0 \\
\end{array}$ \\
\hline $\begin{array}{l}\text { Rotational motion of } \\
\text { the first bogie }\end{array}$ & $\begin{array}{l}J_{t 1} \ddot{\theta}_{t 1}+K_{w 1} L_{t}\left(\theta_{t 1} L_{t}-X_{w 1}\right)+K_{w 2} L_{t}\left(\theta_{t 1} L_{t}+X_{w 2}\right) \\
\quad+C_{w 1} L_{t}\left(\dot{\theta}_{t 1} L_{t}-\dot{X}_{w 1}\right)+C_{w 2} L_{t}\left(\dot{\theta}_{t 2} L_{t}+\dot{X}_{w 2}\right)=0 \\
\end{array}$ \\
\hline $\begin{array}{l}\text { Vertical motion of } \\
\text { the second bogie }\end{array}$ & $\begin{array}{c}M_{t 2} \ddot{X}_{t 2}+K_{t 2}\left(X_{t 2}-X_{c}+\theta_{c} L_{c}\right)+K_{w 3}\left(X_{t 2}-X_{w 3}\right) \\
\quad+K_{w 4}\left(X_{t 2}-X_{w 4}\right)+C_{t 2}\left(\dot{X}_{t 2}-\dot{X}_{c}+\dot{\theta}_{c} L_{c}\right) \\
\quad+C_{w 3}\left(\dot{X}_{t 2}-\dot{X}_{w 3}\right)+C_{w 4}\left(\dot{X}_{t 2}-\dot{X}_{w 4}\right)=0 \\
\end{array}$ \\
\hline $\begin{array}{l}\text { Rotational motion of } \\
\text { the second bogie }\end{array}$ & $\begin{array}{l}J_{t 2} \ddot{\theta}_{t 2}+K_{w 3} L_{t}\left(\theta_{t 2} L_{t}-X_{w 3}\right)+K_{w 4} L_{t}\left(\theta_{t 2} L_{t}+X_{w 4}\right) \\
\quad+C_{w 3} L_{t}\left(\dot{\theta}_{t 2} L_{t}-\dot{X}_{w 3}\right)+C_{w 4} L_{t}\left(\dot{\theta}_{t 2} L_{t}+\dot{X}_{w 4}\right)=0 \\
\end{array}$ \\
\hline $\begin{array}{l}\text { Vertical motion of } \\
\text { the first wheel }\end{array}$ & $\begin{array}{l}M_{w 1} \ddot{X}_{w 1}+K_{w 1}\left(X_{w 1}-X_{t 1}-\theta_{t 1} L_{t}\right) \\
+C_{w 1}\left(\dot{X}_{w 1}-\dot{X}_{t 1}-\dot{\theta}_{t 1} L_{t}\right)+Q_{w 1}=0\end{array}$ \\
\hline $\begin{array}{l}\text { Vertical motion of } \\
\text { the second wheel }\end{array}$ & $\begin{array}{l}M_{w 2} \ddot{X}_{w 2}+K_{w 2}\left(X_{w 2}-X_{t 1}+\theta_{t 1} L_{t}\right) \\
+C_{w 2}\left(\dot{X}_{w 2}-\dot{X}_{t 1}+\dot{\theta}_{t 1} L_{t}\right)+Q_{w 2}=0\end{array}$ \\
\hline $\begin{array}{l}\text { Vertical motion of } \\
\text { the third wheel }\end{array}$ & $\begin{array}{l}M_{w 3} \dot{X}_{w 3}+K_{w 3}\left(X_{w 3}-X_{t 2}-\theta_{t 2} L_{t}\right) \\
+C_{w 3}\left(\dot{X}_{w 3}-\dot{X}_{t 2}-\dot{\theta}_{t 2} L_{t}\right)+Q_{w 3}=0\end{array}$ \\
\hline $\begin{array}{l}\text { Vertical motion of } \\
\text { the fourth wheel }\end{array}$ & $\begin{array}{l}M_{w 4} \ddot{X}_{w 4}+K_{w 4}\left(X_{w 4}-X_{t 2}+\theta_{t 2} L_{t}\right) \\
+C_{w 4}\left(\dot{X}_{w 4}-\dot{X}_{t 2}+\dot{\theta}_{t 2} L_{t}\right)+Q_{w 4}=0\end{array}$ \\
\hline
\end{tabular}


with two layers including the rail and sleeper parts, tracks with three layers including the rail, sleeper and ballast parts, tracks with four layers including the rail, sleeper, ballast and subgrade layers, and tracks with five layers including the rail, sleeper, ballast, subgrade and embankment parts. These track models are presented in Table 2.

Table 2. Railway track multi-layer models



In Table 2, parameters of $M_{R}, M_{S}, M_{B}, M_{S u b}$ and $M_{E}$ are masses of the rail, sleeper, ballast, subgrade, and embankment, respectively. Moreover, $K_{P}, K_{S}, K_{B}, K_{S u b}, K_{E}$ and $K_{T}$ are stiffness of the rail-pad, sleeper, ballast, subgrade, embankment, and railway track support, respectively. In this regard, $C_{P}, C_{S}, C_{B}, C_{S u b}, C_{E}$ and $C_{T}$ are damping coefficients for the 
mentioned track components. For simulating the track models, at first, the equations of each track part are extracted and then the mass, damping and stiffness matrices of the track models are calculated based on the finite element method. According to Table 2, the rail is modeled as a continuous beam, and other railway components are modeled as lumped masses. Moreover, connections between the railway components are springs and dampers (Zakeri et al., 2009, 2016; Mosayebi et al., 2016, 2017). The derived equations of the track layers including one to five layers are presented in Table 3.

Table 3. The derived equations of the railway track parts

\begin{tabular}{|c|c|c|}
\hline $\begin{array}{c}\text { Model } \\
\text { type }\end{array}$ & $\begin{array}{c}\text { Track } \\
\text { layer }(\mathrm{s})\end{array}$ & Equations \\
\hline $\begin{array}{l}\text { One } \\
\text { layer }\end{array}$ & Rail & $M_{R} \ddot{X}_{R}+K_{T} X_{R}+C_{T} \dot{X}_{R}=Q_{w i}, \quad i=1,2,3,4$ \\
\hline $\begin{array}{c}\text { Two } \\
\text { layers }\end{array}$ & Sleeper & $M_{S} \ddot{X}_{S}+K_{P}\left(X_{S}-X_{R}\right)+K_{T} X_{S}+C_{P}\left(\dot{X}_{S}-\dot{X}_{R}\right)+C_{T} \dot{X}_{S}=0$ \\
\hline $\begin{array}{l}\text { Three } \\
\text { layers }\end{array}$ & Ballast & $\begin{array}{c}M_{B} \ddot{X}_{B}+K_{S}\left(X_{B}-X_{S}\right)+K_{T} X_{B}+C_{S}\left(\dot{X}_{B}-\dot{X}_{S}\right) \\
+C_{T} \dot{X}_{B}=0\end{array}$ \\
\hline $\begin{array}{c}\text { Four } \\
\text { layers }\end{array}$ & Subgrade & $\begin{array}{l}M_{S u b} \ddot{X}_{S u b}+K_{B}\left(X_{S u b}-X_{B}\right)+K_{T} X_{S u b} \\
\quad+C_{B}\left(\dot{X}_{S u b}-\dot{X}_{B}\right)+C_{T} \dot{X}_{S u b}=0\end{array}$ \\
\hline $\begin{array}{c}\text { Five } \\
\text { layers }\end{array}$ & Embankment & $\begin{array}{c}M_{E} \ddot{X}_{E}+K_{S u b}\left(X_{E}-X_{S u b}\right)+K_{T} X_{E} \\
\quad+C_{S u b}\left(\dot{X}_{E}-\dot{X}_{S u b}\right)+C_{T} \dot{X}_{E}=0 \\
\end{array}$ \\
\hline
\end{tabular}

In Table $3, X_{R}, X_{S}, X_{B}, X_{S u b}$ and $X_{E}$ are displacements of the rail, sleeper, ballast, subgrade, and embankment, respectively. Moreover, $X_{i}$ and $X_{i}$ are velocities and accelerations of the mentioned track layers, respectively. In the next Section, the equivalent track models is presented.

\section{The equivalent track models and vehicle-track specifications}

From the theoretical point of view, for various equivalent track models, their rail bedding stiffness and damping should be equivalent as a series of springs and dashpots. The equivalent track support stiffness $K_{T}$ and damping $C_{T}$ for each track model are calculated based on Table 4 .

Table 4. The equivalent track support stiffness and damping in the railway track models

\begin{tabular}{|c|c|c|}
\hline $\begin{array}{c}\text { Track } \\
\text { models }\end{array}$ & $\begin{array}{c}\text { Equivalent track support } \\
\text { stiffness } K_{T}\end{array}$ & $\begin{array}{c}\text { Equivalent track support } \\
\text { damping } C_{T}\end{array}$ \\
\hline \hline $\begin{array}{c}\text { One } \\
\text { layer }\end{array}$ & $\frac{1}{K_{T}}=\frac{1}{K_{P}}+\frac{1}{K_{S}}+\frac{1}{K_{B}}+\frac{1}{K_{S u b}}+\frac{1}{K_{E}}$ & $\frac{1}{C_{T}}=\frac{1}{C_{P}}+\frac{1}{C_{S}}+\frac{1}{C_{B}}+\frac{1}{C_{S u b}}+\frac{1}{C_{E}}$ \\
\hline $\begin{array}{c}\text { Two } \\
\text { layers }\end{array}$ & $\frac{1}{K_{T}}=\frac{1}{K_{S}}+\frac{1}{K_{B}}+\frac{1}{K_{S u b}}+\frac{1}{K_{E}}$ & $\frac{1}{C_{T}}=\frac{1}{C_{S}}+\frac{1}{C_{B}}+\frac{1}{C_{S u b}}+\frac{1}{C_{E}}$ \\
\hline $\begin{array}{c}\text { Three } \\
\text { layers }\end{array}$ & $\frac{1}{K_{T}}=\frac{1}{K_{B}}+\frac{1}{K_{S u b}}+\frac{1}{K_{E}}$ & $\frac{1}{C_{T}}=\frac{1}{C_{B}}+\frac{1}{C_{S u b}}+\frac{1}{C_{E}}$ \\
\hline $\begin{array}{c}\text { Four } \\
\text { layers }\end{array}$ & $\frac{1}{K_{T}}=\frac{1}{K_{S u b}}+\frac{1}{K_{E}}$ & $\frac{1}{C_{T}}=\frac{1}{C_{S u b}}+\frac{1}{C_{E}}$ \\
\hline $\begin{array}{c}\text { Five } \\
\text { layers }\end{array}$ & $\frac{1}{K_{T}}=\frac{1}{K_{E}}$ & $\frac{1}{C_{T}}=\frac{1}{C_{E}}$ \\
\hline
\end{tabular}

According to Table 4, the equivalent track support stiffness and damping are determined for various track models. In this regard, the equivalent track support stiffness and damping will be used in the next Section for comparison of the numerical results of multi-layer track 
systems together. Table 5 shows the important range of values for the railway track and vehicle parameters.

Table 5. The railway track and vehicle specifications (Zakeri et al., 2009, 2016; Mosayebi et al., 2016, 2017)

\begin{tabular}{|l|c|l|c|}
\hline \multicolumn{1}{|c|}{ Parameters } & Values & \multicolumn{1}{c|}{ Parameters } & Values \\
\hline \hline Carbody mass $M_{c}$ & $49.3 \cdot 10^{3} \mathrm{~kg}$ & Rail mass $M_{R}$ & $60 \mathrm{~kg} / \mathrm{m}$ \\
\hline Carbody inertia $J_{c}$ & $1700 \cdot 10^{3} \mathrm{~kg} \cdot \mathrm{m}^{2}$ & Rail density $\rho_{R}$ & $7850 \mathrm{~kg} / \mathrm{m}^{3}$ \\
\hline Carbody length $L_{T}$ & $22 \mathrm{~m}$ & Sleeper mass $M_{S}$ & $300 \mathrm{~kg}$ \\
\hline Bogie mass $M_{t}$ & $10.7 \cdot 10^{3} \mathrm{~kg}$ & Rail pad stiffness $K_{p}$ & $60-240 \mathrm{MN} / \mathrm{m}$ \\
\hline Bogie inertia $J_{t}$ & $9.6 \cdot 10^{3} \mathrm{~kg} \cdot \mathrm{m}^{2}$ & Rail pad damping $C_{p}$ & $40-250 \mathrm{kNs} / \mathrm{m}$ \\
\hline $\begin{array}{l}\text { Stiffness between bogie } \\
\text { and carbody } K_{t}\end{array}$ & $1720 \mathrm{kN} / \mathrm{m}$ & Ballast modulus $E_{B}$ & $30-180 \mathrm{MPa}$ \\
\cline { 3 - 4 } $\begin{array}{l}\text { Damping between bogie } \\
\text { and carbody } C_{t}\end{array}$ & \multirow{2}{*}{$300 \mathrm{kNs} / \mathrm{m}$} & Ballast damping $C_{B}$ & $50-200 \mathrm{kNs} / \mathrm{m}$ \\
\cline { 3 - 4 } $\begin{array}{l}\text { Stiffness between wheel } \\
\text { and bogie } K_{w}\end{array}$ & \multirow{2}{*}{$4360 \mathrm{kN} / \mathrm{m}$} & Subgrade modulus $E_{S u b}$ & $60-100 \mathrm{MPa}$ \\
\hline \multirow{2}{*}{$\begin{array}{l}\text { Damping between wheel } \\
\text { and bogie } C_{w}\end{array}$} & \multirow{2}{*}{$220 \mathrm{kNs} / \mathrm{m}$} & Embankment modulus $C_{E}$ & $30-150 \mathrm{kNs} / \mathrm{m}$ \\
\cline { 3 - 4 } & & Hertzian spring $C_{H}$ & $155 \mathrm{MPa}$ \\
\hline
\end{tabular}

In the next Section, field measurements and numerical model validation are presented.

\section{Field measurements and numerical model validation}

In order to obtain the track field responses, some field measurements are taken. The considered ballasted track includes UIC-60 continuous welded rail and wooden sleepers with $60 \mathrm{~cm}$ spacing. In this regard, responses of a track under a moving railway diesel locomotive with the mass of 90 ton and speed of $45 \mathrm{~km} / \mathrm{h}$ are measured by a displacement sensor and accelerometer in the field. Figure 2 shows the moving diesel locomotive for measuring the railway track responses.

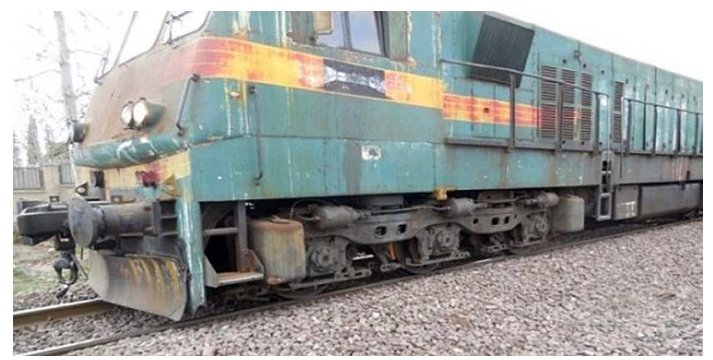

Fig. 2. A moving railway diesel locomotive for measuring track responses (Mosayebi et al., 2016)

After installing the measuring tools on the railway track, the responses are determined. Figure 3 shows the responses of the railway track in the field.

In continuation, results of the track model are validated with the results of field investigations. For this reason, the results of the track model under the moving railway vehicle are compared with the results of field investigations. Figure 4 illustrates the numerical and field results of the railway track displacement (placed above sleeper) due to the moving vehicle by considering the presented conditions.

As can be observed from Fig. 4, there is a good agreement between the results of field and numerical modeling. In continuation, vehicle and track responses are presented for different cases. 
(a)

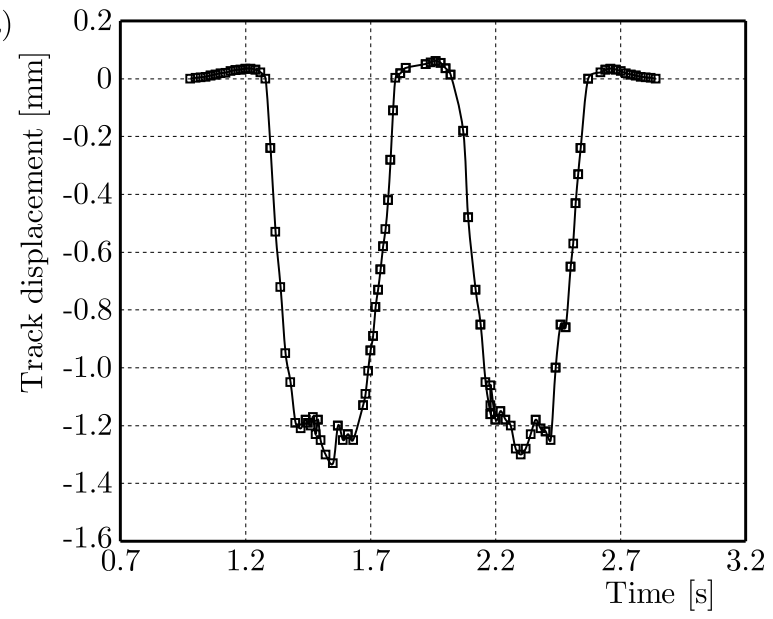

(b)

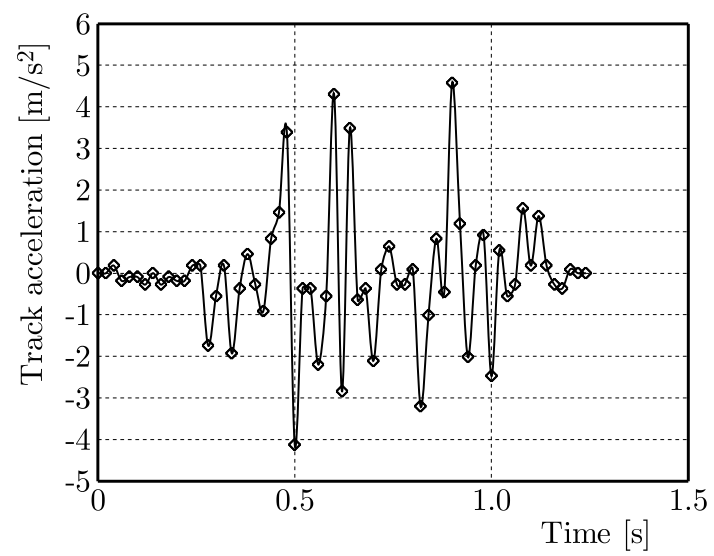

Fig. 3. Track responses under the moving railway vehicle in the field: (a) track displacement, (b) track acceleration

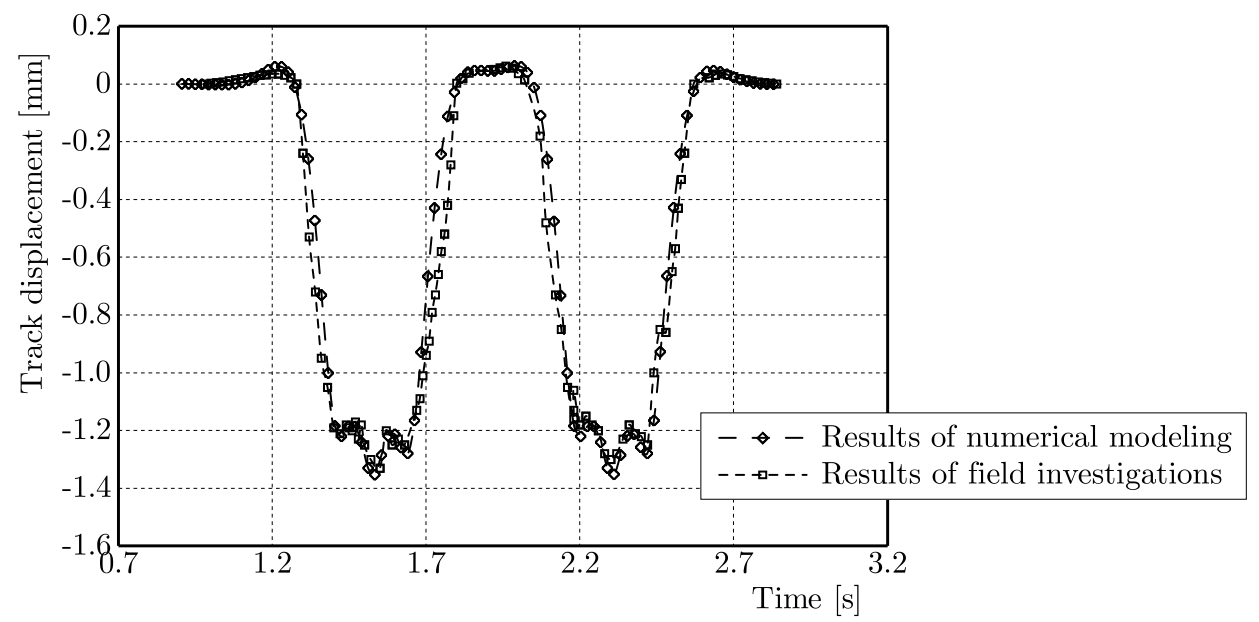

Fig. 4. Validation of the numerical results

\section{Comparison of the vehicle and track responses for various track models}

\subsection{Responses of the railway track models by considering the equivalent method}

In this Section, the responses of various track models caused by a moving vehicle are presented and compared by considering the equivalent method. In this regard, the results of track multi-layer models including the one-layer (rail), two-layer (rail and sleeper), three-layer (rail, sleeper and ballast), four-layer (rail, sleeper, ballast and subgrade), and five-layer (rail, sleeper, ballast, subgrade and embankment) tracks are investigated and compared. Figure 5 illustrates a sample of responses of the mentioned track models under a moving vehicle by considering the equivalent method.

As can be observed from Fig. 5, the peak responses of different track models are the same when the track equivalent method is considered. Moreover, by increasing the number of track components for each model, the responses related to track layers are presented. In continuation, the responses of vehicle-track dynamic interaction are presented for various track model types. 
(a)

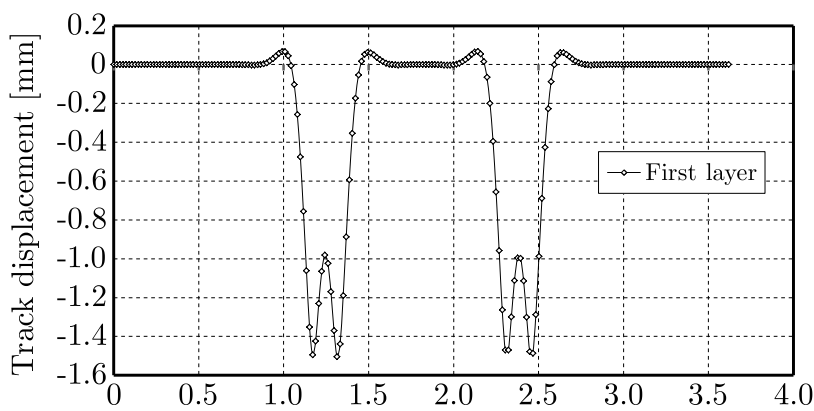

(b)

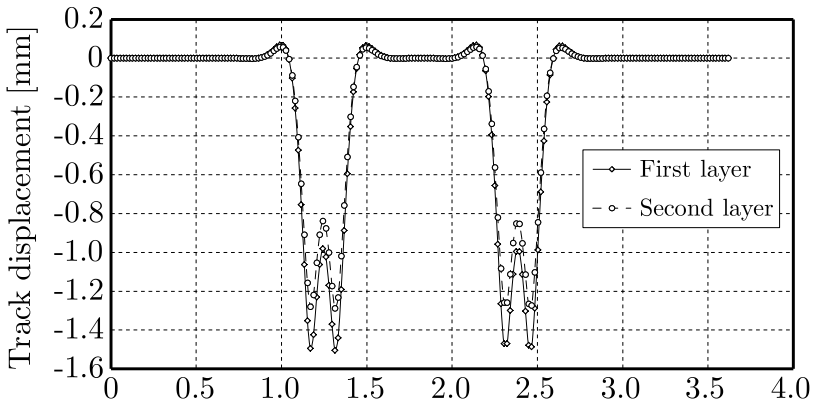

(c)



(d)

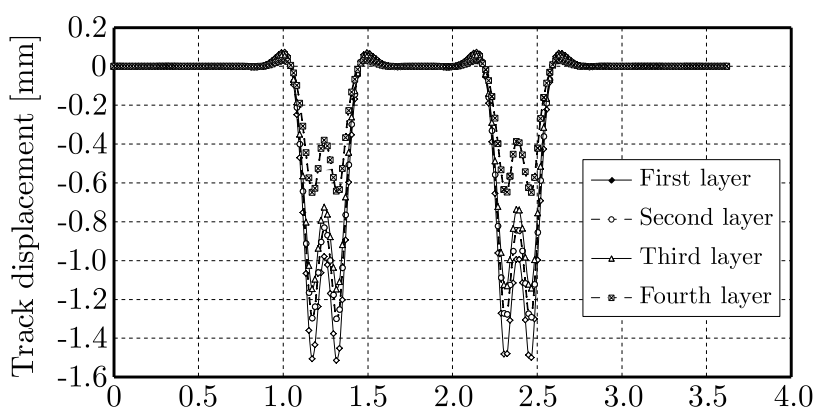

(e)

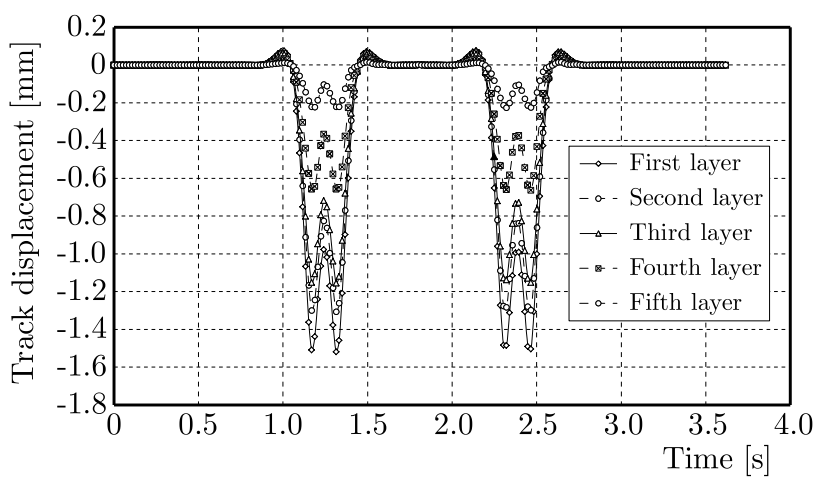

Fig. 5. Responses of the railway track models under a moving vehicle: (a) one layer, (b) two layers, (c) three layers, (d) four layers, (e) five layers 
6.2. Effects of the vehicle and wheel-rail contact force parameters on types of the track model

In this Section, the effects of carbody acceleration and wheel-rail contact force are investigated for various track models. Figures 6 and 7 show the carbody acceleration and the wheel-rail contact force, respectively.

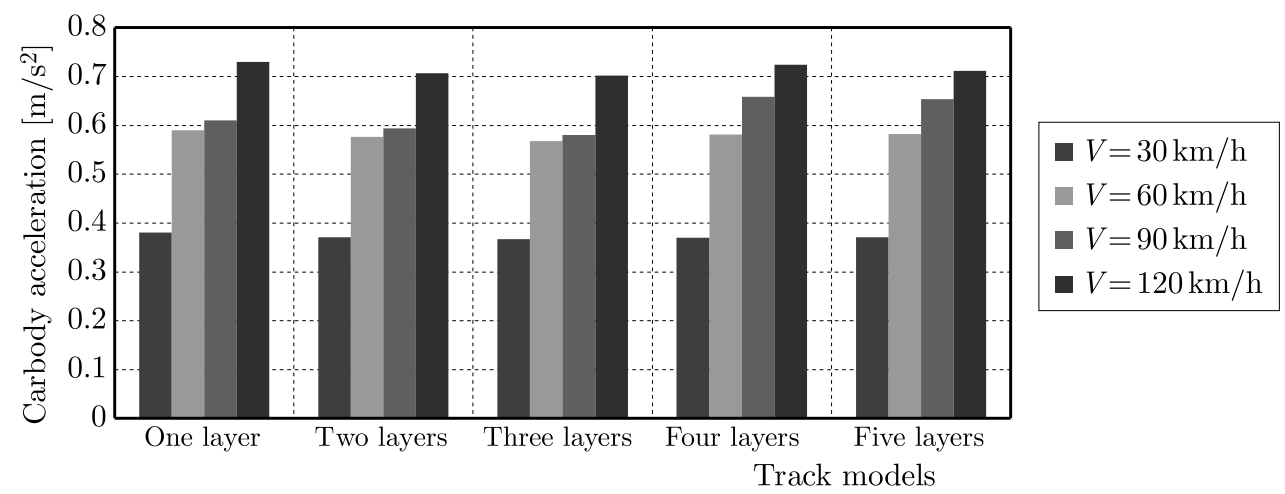

Fig. 6. Carbody acceleration for different track models

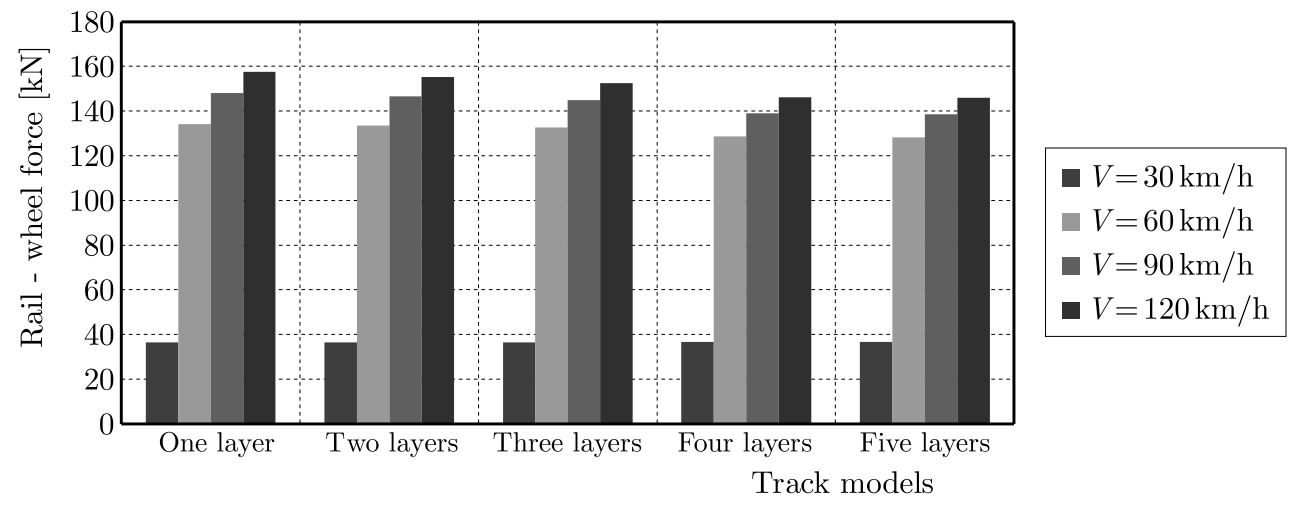

Fig. 7. Wheel-rail contact force for different track models

According to Figs. 6 and 7, there are no significant differences between the track types for estimating the carbody acceleration and the wheel-rail contact force when the equivalent method is used. However, the values of acceleration and the wheel-rail contact force increase with an increase in the vehicle speed for each track model type.

\subsection{Effects of the railway track parameters on types of the track models}

In this Section, the effects of the railway track parameters are studied for different types of track models. In Fig. 8, the results of track support forces are presented for different track models.

As can be observed from Fig. 8, by considering the equivalent method, the track support force for the track models with one, two and three layers is the same in any conditions. Results of the track models with four and five layers are the same at low train speeds in all conditions. However, when train speeds increase, the results are significantly different. Figure 9 illustrates the results of rail velocity for various track models.

According to Fig. 9, there is no considerable difference between the results of the track models relating to the rail velocity in all the conditions. However, by increasing the vehicle speed, the responses increase for each track model type. Figure 10 indicates the rail displacement for various track models. 


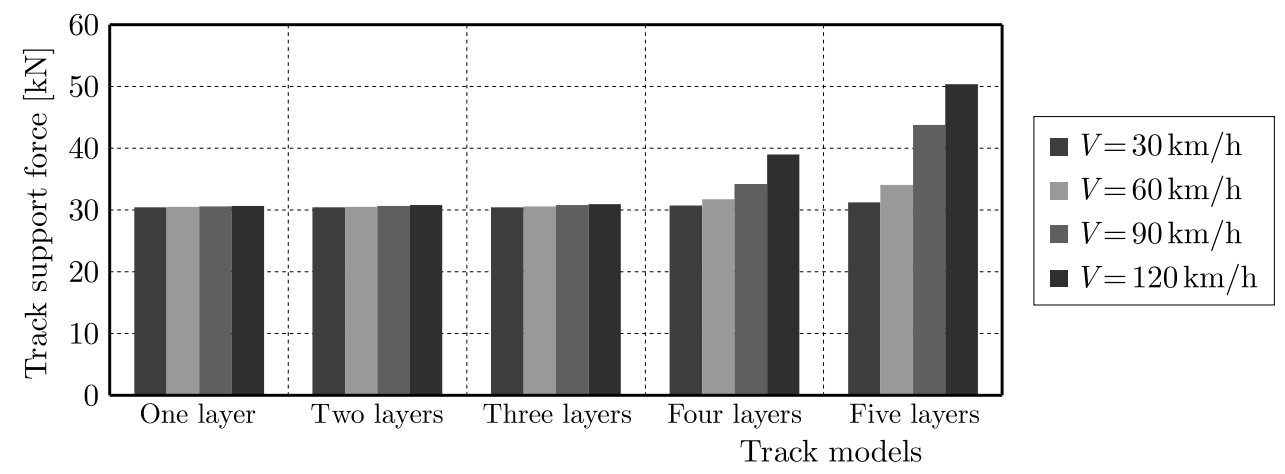

Fig. 8. Track support force for different track models

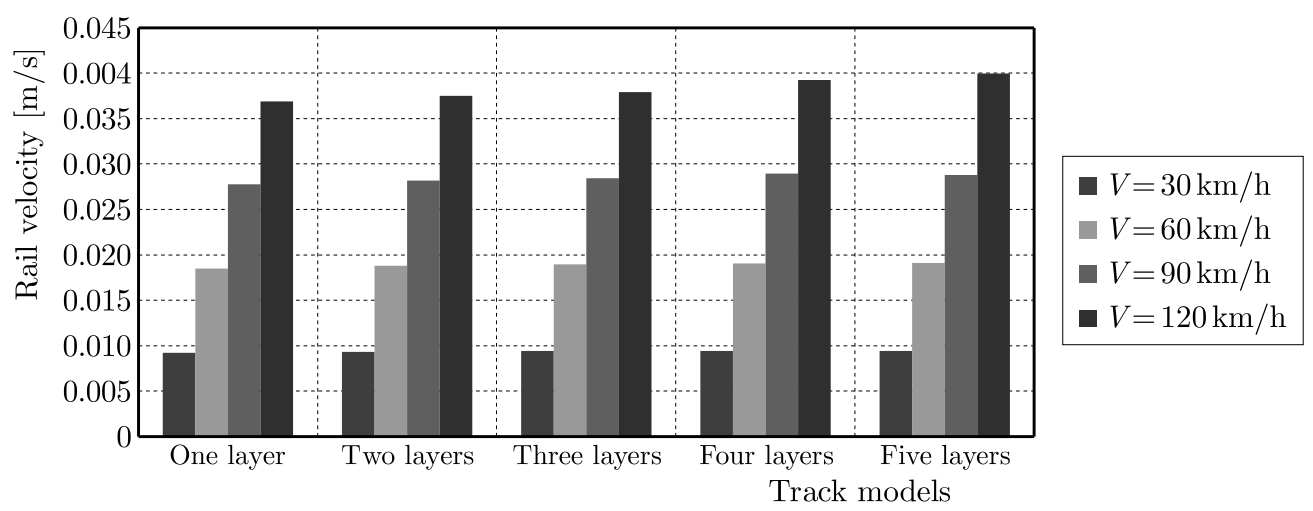

Fig. 9. Rail velocity for different track models

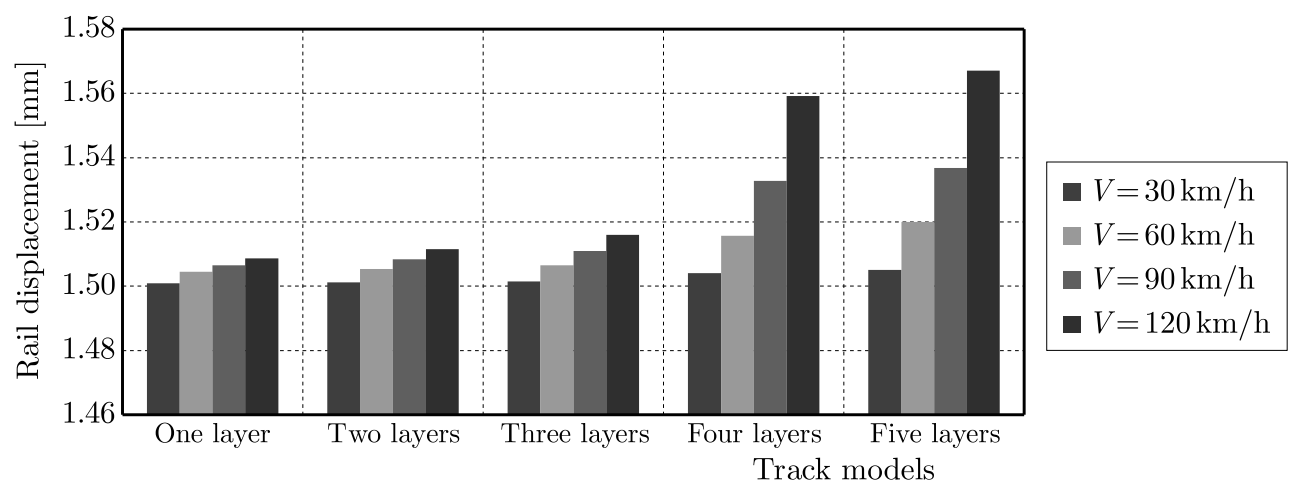

Fig. 10. Rail displacement for different track models

Based on Fig. 10, the rail displacement is the same for the railway models including the tracks with one, two and three layers. However, if the responses related to the tracks with four and five layers are considered, the results are significant between them at high vehicle speeds. Therefore, for obtaining the responses of track components, the tracks with multi layers should be simulated by considering the related track components.

\section{Conclusion}

This research is focused on comparison between vehicle-track dynamic interaction models focusing on track layers. In this paper, at first, a vehicle model with 10 degrees of freedom is presented and its equation of motion is derived. Then, various railway track models are introduced and their equation of motion are derived. Usually, applicable railway track models are 
categorized in five types. These track models are tracks with one to five layers including the rail, sleeper, ballast, subgrade and embankment parts. After validation of a track model caused by a moving railway vehicle with results of field investigations, some studies are performed on various track models. The important results of the paper are summarized as follows:

- The significant differences between the track models do not exist in calculating carbody accelerations and wheel-rail contact forces when the equivalent method is used. However, the values of accelerations and wheel-rail contact forces increase with an increase in the vehicle speed. For instance, the responses of carbody accelerations between the track models with five, four, three, and two layers compared with the track models with one layer differ by $7.2,7.9,4.8$, and $2.6 \%$, respectively, for the vehicle speed of $90 \mathrm{~km} / \mathrm{h}$. These values for wheel-rail contact forces differ by $6.5,6.2,2.25$, and $1 \%$, respectively, for the same track models.

- The track support force responses for the track models with one, two and three layers are the same in all conditions. The results of the track models with four and five layers are the same at low train speeds in all the conditions. However, the difference of the results is significant when train speeds increase. For instance, the responses of track support forces between the track models with five, four, three, and two layers compared with the one-layer track model vary by $43,11.8,0.6$, and $0.23 \%$, respectively, at the vehicle speed of $90 \mathrm{~km} / \mathrm{h}$.

- There is no significant difference between the results of the track models relating to rail velocities and accelerations for tracks without rail irregularity. For example, the responses of rail velocities between the track models with five, four, three, and two layers compared with the one-layer track model differ by $3.3,3,2.3$, and $1.43 \%$, respectively, at the vehicle speed of $60 \mathrm{~km} / \mathrm{h}$. These differences in values of the rail accelerations are 3.1, 2.75, 1.35, and $0.25 \%$, respectively.

- The results of rail displacements between the track model types are significant when the vehicle speed increases. The responses of rail displacements vary between the track models with five, four, three, and two layers compared with the one-layer track model by 2, 1.74, 0.28 , and $0.11 \%$, respectively, at the vehicle speed of $90 \mathrm{~km} / \mathrm{h}$.

- Generally, in railway track problems, the type of the track model should be determined based on the research purpose. However, in every situation for obtaining the responses of track components, tracks with multi layers should be modeled by considering the related track parts.

\section{References}

1. Bogacz R., Czyczuła W., 2008, Response of beam on visco-elastic foundation to moving distributed load, Journal of Theoretical and Applied Mechanics, 46, 4, 763-775

2. Cai Z., Raymond G.P., 1994, Modelling the dynamic response of railway track to wheel/rail impact loading, Structural Engineering and Mechanics, 2, 1, 95-112

3. Dahlberg T., 2001, Some railroad settlement models - a critical review, Proceedings of the Institution of Mechanical Engineers, Part F: Journal of Rail and Rapid Transit, 215, 4, 289-300

4. FrÝBA L., 2013, Vibration of Solids and Structures under Moving Loads, Springer Science \& Business Media

5. KerR A.D., 2000, On the determination of the rail support modulus $k$, International Journal of Solids and Structures, 37, 32, 4335-4351

6. KerR A.D., 2003, Fundamentals of Railway Track Engineering, Simmons-Boardman Books, Incorporated

7. Leaflet No. 301, 2002, Technical and general specification of Ballasted Railway, Management and planning organization of Iran 
8. Montalbán L., Real J., Real T., 2013, Mechanical characterization of railway structures based on vertical stiffness analysis and railway substructure stress state, Proceedings of the Institution of Mechanical Engineers, Part F: Journal of Rail and Rapid Transit, 227, 1, 74-85

9. Mosayebi S.A., Zakeri J.A., Esmaeili M., 2016, Field test investigation and numerical analysis of ballasted track under moving locomotive, Journal of Mechanical Science and Technology, 30, 3, 1065-1069

10. Mosayebi S.A., Zakeri J.A., Esmaeili M., 2017, Vehicle/track dynamic interaction considering developed railway substructure models, Structural Engineering and Mechanics, 61, 6, 775-784

11. Puzavac L., Popović Z., Lazarević L., 2012, Influence of track stiffness on track behaviour under vertical load, PROMET - Traffic and Transportation, 24, 5, 405-412

12. Real J.I., Gómez L., Montalbán L., Real T., 2012, Study of the influence of geometrical and mechanical parameters on ballasted railway tracks design, Journal of Mechanical Science and Technology, 26, 9, 2837-2844

13. Rezvani M.A., Vesali F., Eghbali A., 2013, Dynamic response of railway bridges traversed simultaneously by opposing moving trains, Structural Engineering and Mechanics, 46, 5, 713-734

14. Suzuki T., Ishida M., ABe K., Koro K., 2005, Measurement on dynamic behaviour of track near rail joints and prediction of track settlement, Quarterly Report of RTRI, 46, 2, 124-129

15. Thambiratnam D., Zhuge Y., 1996, Dynamic analysis of beams on an elastic foundation subjected to moving loads, Journal of Sound and Vibration, 198, 2, 149-169

16. Uzzal R.U.A., Ahmed W., Rakheja S., 2008, Dynamic analysis of railway vehicle-track interactions due to wheel flat with a pitch-plane vehicle model, Journal of Mechanical Engineering, 39, 2, 86-94

17. Uzzal R.U.A., Ahmed A.K.W., Rakneja S., 2009, Analysis of pitch plane railway vehicle-track interactions due to single and multiple wheel flats, Proceedings of the Institution of Mechanical Engineers, Part F: Journal of Rail and Rapid Transit, 223, 4, 375-390

18. Wang C., Zhou S., Wang B., Guo P., Su H., 2015, Differential settlements in foundations under embankment load: Theoretical model and experimental verification, Geomechanics and Engineering, 8, 2, 283-303

19. Weining L., He X., Wenjun G., 1996, Study of vibration effects of underground trains on surrounding environments, Chinese Journal of Rock Mechanics and Engineering, 15, S1, 586-593

20. Xia H., Cao Y.M., De Roeck G., 2010, Theoretical modeling and characteristic analysis of moving-train induced ground vibrations, Journal of Sound and Vibration, 329, 7, 819-832

21. Xia H., Deng Y., Xia C., De Roeck G., Qi L., Sun L., 2013, Dynamic analysis of coupled train-ladder track-elevated bridge system, Structural Engineering and Mechanics, 47, 5, 661-678

22. ZAkeri J.A., XiA H., FAn J.J., 2009, Dynamic responses of train-track system to single rail irregularity, Latin American Journal of Solids and Structures, 6, 2, 89-104

23. Zakeri J.A., Mosayebi S.A., Esmaeili M., 2016, Numerical and field investigations of track dynamic behavior caused by light and heavy railway vehicles, Journal of Theoretical and Applied Mechanics, 54, 3, 871-879 